\title{
Topology optimization of nano-photonic systems
}

Elesin, Yuriy; Wang, Fengwen; Andkjær, Jacob Anders; Jensen, Jakob Søndergaard; Sigmund, Ole

Published in:

Advanced Photonics Congress

Publication date:

2012

Document Version

Publisher's PDF, also known as Version of record

Link back to DTU Orbit

Citation (APA):

Elesin, Y., Wang, F., Andkjær, J. A., Jensen, J. S., \& Sigmund, O. (2012). Topology optimization of nanophotonic systems. In Advanced Photonics Congress (pp. IM2B.4). Optical Society of America.

\section{General rights}

Copyright and moral rights for the publications made accessible in the public portal are retained by the authors and/or other copyright owners and it is a condition of accessing publications that users recognise and abide by the legal requirements associated with these rights.

- Users may download and print one copy of any publication from the public portal for the purpose of private study or research.

- You may not further distribute the material or use it for any profit-making activity or commercial gain

- You may freely distribute the URL identifying the publication in the public portal

If you believe that this document breaches copyright please contact us providing details, and we will remove access to the work immediately and investigate your claim 


\title{
Topology optimization of nano-photonic systems
}

\author{
Yuriy Elesin, Fengwen Wang, Jacob Andkjær, Jakob S. Jensen, Ole Sigmund \\ ${ }^{1}$ Department, of Mechanical Engineering, Nils Koppel's Alle b404, 2800 Lyngby, Denmark, \\ yuel/fwan/jban/jsj/sigmund@mek.dtu.dk
}

\begin{abstract}
We describe recent developments within nano-photonic systems design based on topology optimization. Applications include linear and non-linear optical waveguides, slowlight waveguides, as well as all-dielectric cloaks that minimize scattering or back-scattering from hard obstacles.
\end{abstract}

Topology optimization is a way to distribute material in a design domain in order to optimize a given goal function subject to functional or geometrical constraints. The method is based on repeated system analyses (by e.g. Finite Element/Difference approaches in frequency or time domain) followed by deterministic, gradient-based design updates. Originating in mechanical engineering the method has since then been extended to photonic crystal design problems (Ref. 1, 2, 3). An extensive review of the procedure and its applications in nano-photonics has appeared recently (ref. 4). In the present paper we discuss our recent work (developed after ref. 4) within the field. This encompasses improved modeling capabilities for linear and non-linear time domain problems, robustness with respect to manufacturing errors and the systematic design of all-dielectric cloaking devices.

\section{A parallel FDTD code for topology optimization}

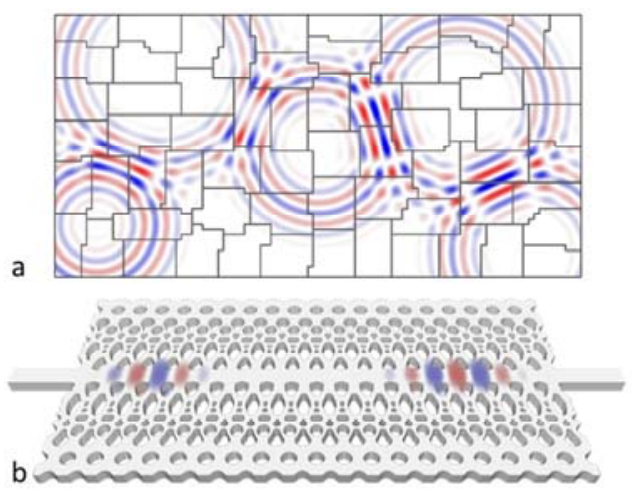

Figure 1 a) Mesh partitioning for distribution of processes on parallel computer. b) Snap-shot of simulations results for $40 \mathrm{M}$ cell $\mathrm{PhC}$ slowlight waveguide test problem.
Topology optimization requires repeated function evaluations and hence especially for $3 \mathrm{~d}$ problems computational efficiency is imperative. For this purpose we have developed an in-house FDTD code that is fully parallelized and which scales linearly on up to 144 CPUs. With the code we can solve 2D problems with $50 \mathrm{k}$ time steps on a $1000 \times 500$ grid in less than 15 seconds and $3 \mathrm{~d}$ problems with $50 \mathrm{k}$ time steps on a $1000 \times 500 \times 80$ grid $(40 \mathrm{M}$ cells) within 40 minutes. Presently, the code is being extended with gradient analysis and topology optimization capabilities and first topology optimization results will be presented at the congress. Mesh partitioning and snap-shot from the modelling of a slow-light photonic crystal-based waveguide is shown in Fig. 1.

\section{Robustness towards manufacturing errors}

Waveguides, resonators and other nano-photonic structures are extremely sensitive to manufacturing uncertainties such as under- or over-etching. We have included such uncertainties in the design process (ref. 5). This is achieved by optimizing for the worst case of the original, under- or overetched structure or by optimizing for the mean performance value with a constraint on the variance.

\section{Topology optimization of non-linear switches}

We have recently extended the topology optimization method to include non-linear nano-photonic problems (ref. 6). Specifically we design a 1D photonic switch where one material is passive (air) and one is Kerr-nonlinear. Compared to a simple Bragg-grating-based switch operating at the band edge we achieve a significant improvement of the switch performance in both open and closed states as demonstrated in Fig. 2. Simultaneously, improved robustness towards manufacturing variation is ensured as described in the previous subsection. 

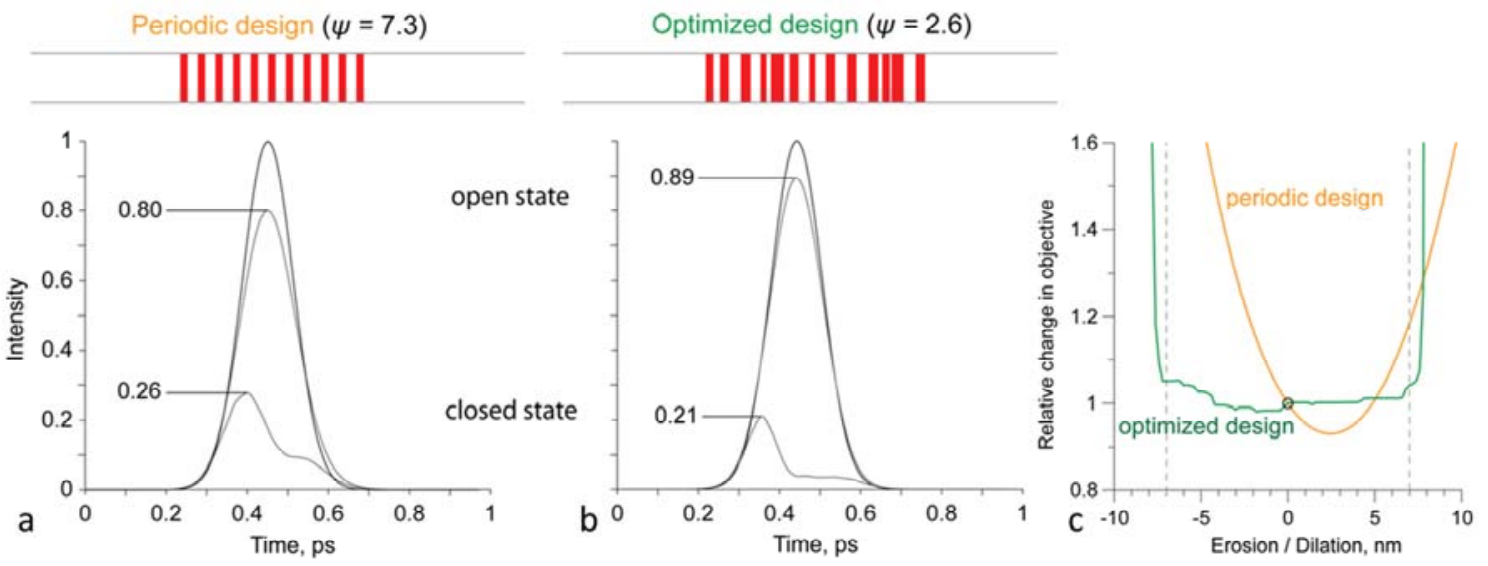

Figure 2 a) Performance in open and closed states for simple Bragg-based non-linear photonic switch. b) Performance of optimized switch. c) Due to the robust optimization approach the optimized switch is less sensitive to under- or overetching.

\title{
Topology optimization of all-dielectric cloaks
}

The art of cloaking, i.e. making objects invisible to the observer by wrapping them in appropriately designed optical cloaks, has received a lot of attention. So-called carpet cloaks can be realized with simply perforated dielectric materials whereas real cloaks (e.g. hiding cylinders) are difficult to realize due to the requirement of extreme electromagnetic material properties. In a number of studies we have used topology optimization to come up with simple dielectric cloaks that perform almost perfectly but only for a limited number of angles (ref. 7). Fig. 3 shows a dielectric cloak design optimized for 2 incoming wave angles. Apart from this full-cloaking example we will show surprisingly simple results obtained for the reduced problem of only considering minimization of back-scattering.
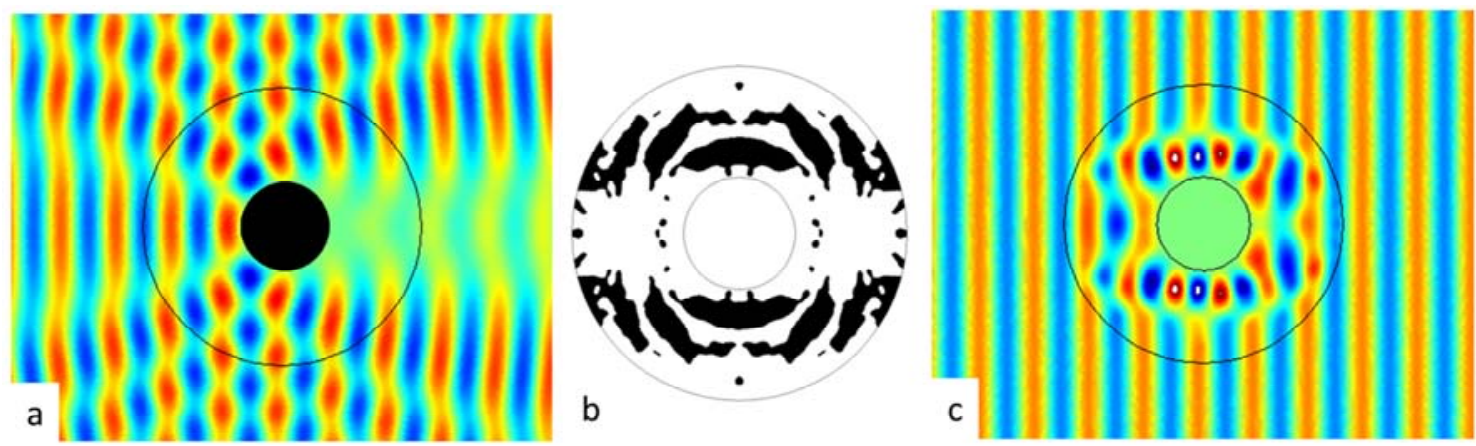

Figure 3 Design of all-dielectric cloak using topology optimization. a) Scattering from hard cylinder. b) Topology optimization dielectric material distribution in cloaking domain (white: air, black: dielectric material, $\varepsilon_{\mathrm{r}}=2$ ). c) Scattering from cloaked cylinder.

\author{
References \\ 1 J.S. Jensen and O. Sigmund, Journal of the Optical Society of America B: Optical Physics, 22, 1191-1198 (2005). \\ 2 O. Sigmund and K. Hougaard, Physical Review Letters, 100, 153904 (2008). \\ ${ }^{3}$ R. Matzen, J.S. Jensen and O. Sigmund, Journal of the Optical Society of America B, 28, 2374-2382 (2011). \\ 4 J.S. Jensen, J. and O. Sigmund, O., Laser \& Photonics Reviews, 5, 308-321 (2011). \\ ${ }^{5}$ F. Wang, B.S. Lazarov and O. Sigmund, Structural and Multidisciplinary Optimization, 43, 767-784 (2011). \\ ${ }^{6}$ Y. Elesin, B.S. Lazarov, J.S. Jensen and O. Sigmund, Photonics and Nanostructures (2012). \\ 7 J. Andkjær and O. Sigmund, Applied Physics Letters, 98, 021112 (2011).
}

